\title{
Variation in Medication Therapy Management Delivery: Implications for Health Care Policy
}

\author{
Margie E. Snyder, PharmD, MPH, FCCP; Heather A. Jaynes, RN, MSN; \\ Stephanie A. Gernant, PharmD, MS; Wendy M. Lantaff, PharmD, MS, BCACP; \\ Karen Suchanek Hudmon, DrPH, MS, RPh; and William R. Doucette, PhD
}

\begin{abstract}
BACKGROUND: Medication therapy management (MTM) program evaluations have revealed mixed outcomes, with some studies finding favorable outcomes and others finding no differences between patients who received MTM versus those who did not. One possible reason for outcomes variability is differences in delivery of MTM programs. The Chronic Care Model (CCM) provides a framework for how health care organizations can improve care for the chronically ill through 6 elements: organization of health care, delivery system design, clinical information systems, decision support, self-management, and linkages to community resources.
\end{abstract}

OBJECTIVE: To apply the CCM to understand variation in MTM delivery and formulate policy recommendations.

METHODS: This study used a mixed-methods descriptive analysis of MTM delivery. Investigators conducted visits to a purposeful sample of MTM practices to observe MTM and interview participants. The pharmacists and staff of these practices completed a modified Assessment of Chronic IIIness Care (ACIC). Pairs of investigators analyzed interview transcripts to identify themes. Demographics and ACIC scores were summarized using descriptive statistics. After analysis, investigators discussed overarching themes and policy implications organized by CCM elements.

RESULTS: Seven practices participated, and 87 participants were interviewed. Based on ACIC scores, MTM patient volume, and payer mix, practices were categorized as Early Maturity Level or Later Maturity Level. From the model, organization of health care themes included whether MTM was the practice's core competence, belief/confidence in the MTM process, lack of formal rewards, and the influence of organizational goals and external environment. Delivery system design themes pertained to the extent that MTM processes were formalized. Clinical information systems themes were the extent to which systems were influenced by payers, efficiency strategies, and the accuracy and availability of information. In considering clinical decision support themes, alert design limitations and variation in user approaches to alerts based on experience were noted. We observed strong support for patient self-management; when present, barriers were attributed to the patient, MTM provider, or payer. Referral to community resources was minimal. Numerous policy implications were identified.

CONCLUSIONS: Our research identified numerous ways by which MTM delivery varies, particularly by MTM practice maturity level. These findings provide evidence for several policy changes that could be considered to optimize MTM delivery, encourage alignment with the CCM, and promote practice maturation.

J Manag Care Spec Pharm. 2018;24(9):896-902

Copyright $\odot 2018$, Academy of Managed Care Pharmacy. All rights reserved.

\section{What is already known about this subject}

Outcomes of medication therapy management (MTM) program evaluations have varied.

A 2014 systematic review conducted by the Agency for Healthcare Research and Quality found insufficient evidence regarding the effectiveness of MTM for most outcomes.

Outcomes variation might be due in part to variation in MTM delivery.

\section{What this study adds}

MTM delivery varies, particularly by where a practice is in its development, and there are numerous policy implications.

Later Maturity Level practices had more formalized processes for using support staff, conducting training, and engaging patients in MTM.

Payer mix influenced practice maturity and, consequently, patient volumes and work processes as well as use of clinical information systems and clinical decision support.

$\mathrm{M}$ edicare Part D has been in existence for 12 years, and while considered successful in improving access to medications, ${ }^{1}$ one component, medication therapy management (MTM), is underused among eligible beneficiaries, and its outcomes are variable. ${ }^{2-4}$ MTM is defined broadly as "a service or group of services provided by pharmacists to optimize therapeutic outcomes for individual patients" and consists of a medication therapy review, which can be a comprehensive medication review (CMR) or a targeted medication review (TMR) ${ }^{5}$; provision of a personal medication record and medication-related action plan to the patient; intervention/referral to resolve identified medication-related problems; and documentation and follow-up. ${ }^{6}$ MTM aims to improve collaboration among health care providers and patients and optimize medication use for improved patient outcomes. ${ }^{6}$ Currently, Medicare Part D MTM programs are required to offer eligible beneficiaries an annual CMR and quarterly TMRs. ${ }^{7}$ Corresponding program evaluations have revealed mixed outcomes, with some studies finding favorable outcomes and others finding no differences between patients who received MTM versus those who did 
not. ${ }^{8-10}$ One possible reason for outcomes variability is differences in the delivery of MTM programs. For example, some sponsors contract with community pharmacists to deliver MTM services, while others use call centers. ${ }^{11}$ Similarly, some MTM providers serve patients nationally and others a single community. Moreover, use of support staff varies. In 2014, a systematic review conducted by the Agency for Healthcare Research and Quality found insufficient evidence regarding the effectiveness of MTM for most outcomes. ${ }^{3,4}$ In response to the addition of CMR completion rates to Medicare Part D plans' star measures in 2016,12 increases in completion rates are expected. However, this measure focuses on quantity, not quality, and therefore might not positively influence patient outcomes.

The Chronic Care Model (CCM) provides a framework for how health care organizations can improve care for the chronically ill through 6 elements: delivery system design, organization of health care, clinical information systems, decision support, self-management, and linkages to community resources. ${ }^{13,14}$ Given Medicare Part D's focus on providing MTM to patients with 2 or more chronic conditions, the objective of this study was to apply the CCM to improve understanding of the operations of existing MTM programs, characterize ways by which MTM delivery varies, and formulate recommendations for MTM policy that could optimize patient outcomes. Recent efforts to develop a new conceptual framework for MTM research by integrating CCM concepts provide support for this approach. ${ }^{15}$

\section{Methods}

\section{Study Overview and Site Selection}

Applying a multimethod approach, data were collected from a purposeful national sample of 7 pharmacy practices that reported providing MTM through Medicare Part D. ${ }^{16}$ The 7 practices represented a diverse cross-section of practice types, geography (5 states represented), and experience with MTM delivery. As described in a previous paper, practices were identified through the Medication Safety Research Network of Indiana (Rx-SafeNet) and leadership from the Minnesota Pharmacy Practice-based Research Network, as well as through the investigators' professional networks. ${ }^{17-19}$ Five practices were community-based (i.e., traditional community pharmacies or the outpatient pharmacy team of an integrated health system) and 2 were call centers. Two to 3 investigators (Snyder, Jaynes, and Gernant) traveled to each practice over a 2- to 3-day period between fall 2013 and spring 2015 to (a) administer a modified Assessment of Chronic Illness Care survey (ACIC); (b) observe MTM delivery and conduct contextual inquiry; and (c) interview participants, including pharmacists, pharmacy staff, prescribers, and patients, involved in or receiving MTM. ${ }^{20,21}$ During visits, investigators audio-recorded daily debriefs of their observations. Study procedures were approved by the Purdue University Institutional Review Board and participants provided written informed consent.

\section{Data Collection}

Assessment of Chronic Illness Care. Upon arrival at each practice, a modified ACIC version 3.5 was administered on paper to participating pharmacists and practice staff, with the intent it be completed at that time (available from the authors by request). ${ }^{20}$ The ACIC is a 34-item, 3-part assessment addressing (a) the organization's health care delivery system; (b) community linkages; and (c) practice-level items regarding patient self-management support, decision support, delivery system design, clinical information systems, and integration of CCM elements. ${ }^{21}$ Each item inquired about support for chronic illness care and was rated from 0 (lowest possible score corresponding to limited support) to 11 (highest possible score indicating optimal support). ACIC modifications involved wording only and investigators obtained permission to modify.

Observations and Contextual Inquiry. During visits, researchers observed MTM activities and engaged pharmacists and practice staff in audio-recorded contextual inquiries, during which researchers asked directed questions to gain insight regarding MTM workflow and decision making and supplemented with researchers' written notes. ${ }^{22-25}$ Contextual inquiries occurred before (e.g., reviewing patient information) and after (e.g., preparing medication-related action plans and personal medication lists) TMRs and CMRs. Investigators also timed a purposeful sample of MTM activities observed, as described previously. ${ }^{17}$

Semistructured Interviews. During 30- to 60-minute semistructured audio-recorded interviews with participants, researchers used interview guides with open-ended questions designed to characterize the MTM delivery process, focusing on CCM elements. Participant demographics were collected following each interview. Interview guides were pilot tested with 2 to 4 individuals of each participant type. Pilot testing was not conducted at participating practices, and pilot data were not included in analyses.

\section{Data Analysis}

Qualitative Data. Interviews, contextual inquiries, and investigator debriefs were transcribed verbatim by medical transcriptionists and reviewed by investigators for accuracy. Transcripts were then coded with MAXQDA versions 10 through 12 qualitative data analysis software (VERBI GmbH, Berlin, Germany). Deductive and inductive approaches established the coding structure. ${ }^{26}$ Data were first grouped by broad conceptual codes mirroring the elements of the CCM, and subcodes were created inductively (i.e., in response to emergent data). Consensus was used to finalize all codes. To ensure coding reliability, 
2 researchers individually coded each transcript and reconciled any discrepancies via discussion. In total, 4 study team members participated in coding (Snyder, Jaynes, Gernant, and Lantaff). Intercoder reliability was evaluated for a sample of broad codes through calculation of Cohen's kappa at coding midpoint. ${ }^{27}$ Repeat interviews were not conducted and member checking was not performed. ${ }^{28}$

Quantitative Data. To summarize demographics and ACIC scores, descriptive statistics were computed using SPSS v. 24 (IBM Corp., Armonk, NY). Time data were analyzed using a time-and-motion approach and reported elsewhere. ${ }^{17}$ Due to the qualitative nature of this investigation and small sample sizes, no tests of significance were performed.

Data Synthesis and Identification of Policy Implications. To summarize intrapractice themes, site summaries were prepared for each practice. At the conclusion of coding and site-summary preparation, 5 investigators (Snyder, Jaynes, Gernant, Lantaff, and Doucette) collectively discussed and summarized overarching themes and policy implications, organized by each CCM element.

\section{Results}

\section{Participant and Practice Characteristics}

Investigators spent an estimated 312 combined hours at MTM practices, and 174 transcripts were produced and analyzed from 87 participants (Table 1). As described in a previous paper, and using the Capability Maturity Model as a guide, ${ }^{17,29} 2$ practice maturity levels (not necessarily synonymous with length of time providing MTM), Early Maturity Level $(\mathrm{n}=3)$ and Later Maturity Level $(n=4)$, were evident based on (a) MTM patient volume, (b) payer mix, and (c) ACIC scores. Compared to Early Maturity Level practices, Later Maturity Level practices exhibited higher mean ACIC scores, larger per-pharmacist, per-week MTM patient volumes, and a smaller proportion of MTM cases paid by Medicare Part D plans. ${ }^{17}$

\section{Themes by CCM Element and Differences Across Practice Maturity}

Cohen's kappa was 0.83 , signifying strong agreement across coders. Major themes are summarized in Table 2.

Organization of Health Care. Themes included (a) whether MTM was considered a "core competence" (i.e., the focus of the organization) versus a value-added service and whether CMRs or TMRs were emphasized; (b) the confidence expressed by participants in their MTM process, with Later Maturity Level practices expressing greater confidence; (c) use of informal rather than formal performance rewards across both practice maturity levels (the use of incentives to influence performance is suggested by the CCM); (d) MTM goals (i.e., what the organization aimed to achieve through MTM delivery); and (e) external environment influences (e.g., MTM payer mix) on
TABLE 1 Practice Characteristics by Level of Practice Maturity

\begin{tabular}{|c|c|c|c|c|}
\hline & \multicolumn{4}{|c|}{ Practice Level of Maturity } \\
\hline & \multicolumn{2}{|c|}{$\begin{array}{l}\text { Early Maturity } \\
\text { Level }(\mathbf{n}=3)\end{array}$} & \multicolumn{2}{|c|}{$\begin{array}{l}\text { Later Maturity } \\
\text { Level }(n=4)\end{array}$} \\
\hline \multicolumn{5}{|l|}{ Type of practice, n (\%) } \\
\hline Call center & 1 & $(33.3)$ & 1 & $(25.0)$ \\
\hline Community & 2 & $(66.7)$ & 3 & $(75.0)$ \\
\hline \multicolumn{5}{|l|}{ Practice's core competence, $\mathrm{n}(\%)$} \\
\hline MTM & 0 & $(0.0)$ & 2 & $(50.0)$ \\
\hline Dispensing & 3 & $(100.0)$ & 0 & $(0.0)$ \\
\hline Both (MTM/dispensing) & 0 & $(0.0)$ & 2 & $(50.0)$ \\
\hline \multicolumn{5}{|c|}{ Number of staff observed per practice, median (range) } \\
\hline Pharmacist & 2.3 & $(1.0-4.0)$ & & $(5.0-7.0)$ \\
\hline Support staff & 1.7 & $(1.0-2.0)$ & 5 & $(2.0-9.0)$ \\
\hline \multicolumn{5}{|c|}{$\begin{array}{l}\text { Per practice MTM appointments conducted/involved with per week, } \\
\text { median (range) }\end{array}$} \\
\hline Pharmacists & \multicolumn{2}{|c|}{$1.2(0.0-10.0)$} & \multicolumn{2}{|c|}{$7.5(1.0-72.0)$} \\
\hline Support staff & \multicolumn{2}{|c|}{$4.0(0.0-10.0)$} & \multicolumn{2}{|c|}{$19.0(1.1-30.0)$} \\
\hline \multicolumn{5}{|c|}{ Per practice years providing/supporting MTM, median (range) } \\
\hline Pharmacists & \multicolumn{2}{|c|}{$4.5(0.3-8.0)$} & \multicolumn{2}{|c|}{$4.0 \quad(3.0-9.0)$} \\
\hline Support staff & \multicolumn{2}{|c|}{$0.1 \quad(0.0-5.0)$} & \multicolumn{2}{|c|}{$1.3(0.2-13.0)$} \\
\hline $\begin{array}{l}\text { Per practice \% of appointments, } \\
\text { Medicare Part D, mean (SD) }\end{array}$ & \multicolumn{2}{|c|}{$66.7 \quad(57.7)$} & \multicolumn{2}{|c|}{$62.0 \quad(43.4)$} \\
\hline $\begin{array}{l}\text { Per practice overall mean ACIC score, } \\
\text { mean (SD) }\end{array}$ & \multicolumn{2}{|c|}{$6.4 \quad(2.3)$} & \multicolumn{2}{|l|}{8.2} \\
\hline Pharmacists & \multirow{2}{*}{\multicolumn{2}{|c|}{$\frac{6.3}{7.0}$}} & \multirow{2}{*}{\multicolumn{2}{|c|}{$\begin{array}{ll}7.6 & (1.7) \\
8.4 & (1.6) \\
\end{array}$}} \\
\hline Support staff & & & & \\
\hline Total number of participants, $n$ & \multicolumn{2}{|c|}{24} & \multicolumn{2}{|c|}{63} \\
\hline Pharmacists, $\mathrm{n}(\%)^{\mathrm{a}}$ & 7 & $(29.2)$ & 24 & $(38.1)$ \\
\hline Support staff, n (\%) & 5 & $(20.8)$ & 20 & $(31.7)$ \\
\hline Providers, n (\%) ${ }^{\mathrm{b}}$ & 2 & $(8.3)$ & 1 & $(1.6)$ \\
\hline Patients, n (\%) & 10 & $(41.7)$ & 18 & $(28.6)$ \\
\hline Age, mean per practice (SD) & 50.4 & $(9.7)$ & 43.7 & $(9.3)$ \\
\hline Pharmacists & 50.1 & (3.4) & 36.5 & $(1.9)$ \\
\hline Support staff & 28.5 & $(12.3)$ & 32.3 & $(5.4)$ \\
\hline Patients & 72.7 & $(4.2)$ & 68.5 & $(13.7)$ \\
\hline Sex, female, mean \% per practice (SD) & 47.2 & (12.7) & 78.9 & $(12.9)$ \\
\hline Pharmacists & 33.3 & $(28.9)$ & 78.2 & $(15.7)$ \\
\hline Support staff & 50.0 & $(50)$ & 81.3 & $(14.2)$ \\
\hline Patients & 55.8 & $(17.1)$ & 77.8 & $(15.7)$ \\
\hline $\begin{array}{l}\text { Race, Caucasian, mean \% per } \\
\text { practice (SD) }\end{array}$ & 89.2 & (12.9) & 92.4 & $(5.4)$ \\
\hline Pharmacists & 92.4 & (13.3) & 100.0 & $(0.0)$ \\
\hline Support staff & 82.8 & $(30.6)$ & 92.1 & $(7.8)$ \\
\hline Patients & 92.3 & (13.3) & 82.8 & (11.8) \\
\hline $\begin{array}{l}\text { Pharmacists with PharmD degree, } \\
\text { mean \% per practice (SD) }\end{array}$ & 25.0 & (43.3) & 86.7 & (16.3) \\
\hline \multicolumn{5}{|c|}{$\begin{array}{l}\text { aOne additional pharmacist was interviewed in the Later Maturity Level group, } \\
\text { but the data were lost before the analysis and therefore were not included. } \\
\text { bDue to small sample sizes for providers, demographics were not reported. } \\
\text { ACIC=Assessment of Chronic Illness Care; MTM=medication therapy } \\
\text { management; SD = standard deviation. }\end{array}$} \\
\hline
\end{tabular}

MTM opportunities (i.e., appointment volume), use of specific clinical information systems, and the way in which practices deliver care (i.e., extent of formalized systems). 


\begin{tabular}{|c|c|c|}
\hline TABLE 2 & \multicolumn{2}{|c|}{$\begin{array}{l}\text { Major Themes by Chronic Care Model } \\
\text { Element }\end{array}$} \\
\hline CCM Element & Major Themes & $\begin{array}{l}\text { Early Maturity Level vs. } \\
\text { Later Maturity Level }\end{array}$ \\
\hline $\begin{array}{l}\text { Organization of } \\
\text { health care }\end{array}$ & $\begin{array}{l}\text { - MTM as core } \\
\text { competence } \\
\text { - Belief/confidence in } \\
\text { MTM process } \\
\text { - Lack of formal rewards } \\
\text { - Organizational goals } \\
\text { - External environment }\end{array}$ & $\begin{array}{l}\text { - Later Maturity Level } \\
\text { practices were confident } \\
\text { in MTM provided at their } \\
\text { organization } \\
\text { - Later Maturity Level } \\
\text { practices were split on } \\
\text { emphasizing CMRs vs. } \\
\text { TMRs; some didn't sched- } \\
\text { ule CMRs due to inef- } \\
\text { ficiencies if patients did } \\
\text { not show }\end{array}$ \\
\hline $\begin{array}{l}\text { Delivery system } \\
\text { design }\end{array}$ & $\begin{array}{l}\text { - Formalization regarding: } \\
\text { o Use of support staff } \\
\text { o Training } \\
\text { o Patient engagement }\end{array}$ & $\begin{array}{l}\text { - Later Maturity Level prac- } \\
\text { tices had more formalized } \\
\text { processes and support } \\
\text { staff and were more likely } \\
\text { to contribute to patient } \\
\text { recruitment, documenta- } \\
\text { tion, and billing }\end{array}$ \\
\hline $\begin{array}{l}\text { Clinical } \\
\text { information } \\
\text { systems }\end{array}$ & $\begin{array}{l}\text { - Influence of external } \\
\text { environment } \\
\text { - Strategies for efficiency } \\
\text { - Accuracy and availabil- } \\
\text { ity of information }\end{array}$ & $\begin{array}{l}\text { - Early Maturity Level } \\
\text { practices relied more on } \\
\text { payer billing platforms for } \\
\text { documentation }\end{array}$ \\
\hline $\begin{array}{l}\text { Clinical } \\
\text { decision } \\
\text { support }\end{array}$ & $\begin{array}{l}\text { - Design implications } \\
\text { - User approach }\end{array}$ & $\begin{array}{l}\text { - None noted; differences } \\
\text { appeared to be influenced } \\
\text { by individual participant } \\
\text { experience with MTM }\end{array}$ \\
\hline $\begin{array}{l}\text { Self- } \\
\text { management } \\
\text { support }\end{array}$ & $\begin{array}{l}\text { - When present, barriers } \\
\text { pertained to: } \\
\text { o Patient } \\
\text { o MTM provider } \\
\text { o Payer }\end{array}$ & $\begin{array}{l}\text { - Later Maturity Level prac- } \\
\text { tices emphasized chal- } \\
\text { lenges with CMS required } \\
\text { formats for medication } \\
\text { action plan and personal } \\
\text { medication list } \\
\text { - Later Maturity Level } \\
\text { practices had more robust } \\
\text { follow-up procedures }\end{array}$ \\
\hline $\begin{array}{l}\text { Linkages to } \\
\text { community } \\
\text { resources }\end{array}$ & - Underuse & $\begin{array}{l}\text { - Across all practices, com- } \\
\text { munity resources were } \\
\text { underused due to lack of } \\
\text { familiarity or because not } \\
\text { perceived as part of MTM }\end{array}$ \\
\hline & 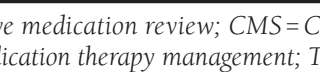 & $\begin{array}{l}\text { ers for Medicare \& Medicaid } \\
=\text { targeted medication review. }\end{array}$ \\
\hline
\end{tabular}

Delivery System Design. MTM process formalization varied considerably, particularly in use of support staff and approaches to training and patient engagement. This was driven by the goals and core competency of the organization and level of practice maturity. For example, support staff, such as pharmacy technicians and interns, contributed to patient recruitment, documentation, and billing activities primarily at Later Maturity Level practices. Early Maturity Level practices used support staff less consistently and with less structure. Also, Later Maturity Level practices had more formalized training and quality assurance processes, as well as multiple modalities for patient recruitment, including scripted invitation language. As described by a participant from a Later Maturity Level practice, "I think the success comes from [having a] consistent care model... and having our pharmacists use that care model and do an assessment in the same way...we train all of them to make sure they they're following that same approach."

Clinical Information Systems. These systems were frequently influenced by payers, as the payer often dictates the use of specific billing systems, which are used as documentation platforms. This often resulted in the need to use multiple computerized systems to deliver MTM, creating inefficiencies. As described by one participant, "We work with 6 different payer systems to bill our time. It's a burden to go in there to each different one." The extent to which payers' systems versus others were used was driven by the organization's core competency and maturity level. Some practices, particularly Early Maturity Level, used the payers' systems exclusively whereas others created internal proprietary systems. In addition, pharmacists and practice staff described variation in approaches to using computerized systems efficiently (e.g., documenting during the patient visit) and in the quality/availability of patient information (e.g., laboratory data).

Clinical Decision Support. Given that clinical information systems often include integrated clinical decision support (CDS), payers also influence the use of CDS in MTM. Participants also commented on design implications (e.g., alerts falsely identifying medication-related problems) of CDS. As one participant said, "If it's a brand name medication, and patients are getting some free samples from doctors, and they really are adherent, and even though our system pops that flag saying, 'oh, they're not'...well, they do have their medication, they just got [it] from another source." Users also varied in approach to CDS. Whereas pharmacists often made decisions independent of CDS, paid interns and pharmacy rotation students (i.e., more novice professionals) often relied heavily on CDS. As stated by one pharmacy student at an Early Maturity Level practice, "That is something we didn't ask in our first 2 [CMRs] this morning, because we weren't prompted to." Similarly, an intern at a Later Maturity Level practice said, "If those things were issues, the alerts would fire."

Self-Management. Evidence for strong patient self-management was pervasive; when barriers to self-management existed, they pertained to patients (e.g., lack of engagement), MTM providers (e.g., lack of patient education materials available), and payers (e.g., concern with Centers for Medicare \& Medicaid Services [CMS] required documentation formats and the lack of paid follow-up appointments might have limited follow-up at Early Maturity Level practices). One pharmacist at a Later Maturity Level practice described concern with the CMS required format: "I have several gripes about that documentation. It's pages, and pages, and pages long....the font's really large. And I understand why...just to make sure everyone can read it, but... it really adds up; I think it's overwhelming to people." 
Linkages to Community Resources. Across both maturity levels, links to community resources were underused because of either a lack of familiarity with available resources (e.g., because the participant practiced at a call center or was a student on a brief rotation at the practice) or a perception that such referrals are not a part of MTM. Lack of CDS specific to community resource linkages may have also contributed to underuse and perceptions that these referrals fall outside the scope of MTM, particularly among users who are more heavily reliant on CDS. As said by one pharmacist, "We haven't sent people to most of those programs. Most of the MTMs...those things too can start from the doctor's office... you know, the doctor tells the patient they need to lose weight, the doctor tells the patient they need to stop smoking.... I've had very few MTMs that related around smoking...MTM doesn't push us in a way...for health and wellness very well." Similarly, another pharmacist said, "We know of all those resources and if there's something that's outside our scope of the MTM...we could talk about some of those things, but in the normal course of an MTM, it's not really an issue."

\section{Discussion}

Our research identified numerous ways by which MTM delivery varies, particularly by MTM practice maturity level. These findings provide evidence for several policy changes that could be considered to optimize MTM delivery, encourage alignment with the CCM, and promote practice maturation.

First, policies could be implemented that separate the payer from the choice of MTM documentation system used. Practices need the ability to choose computerized systems that best meet their needs rather than be required to use payer/vendor-proprietary systems. Across practices, inefficiencies were introduced because of the need to access multiple systems. MTM systems chosen by the practice would also benefit from a capability to integrate with dispensing systems to mitigate this issue. In addition, computerized systems sometimes integrate CDS, which might be designed for payer needs (e.g., cost containment), rather than provider, practice, or patient priorities. For example, pharmacists described some alerts as not being clinically relevant. Not only are these alerts inefficient, but they could reduce patient engagement, because patients might not understand why MTM was offered or why they are asked specific, potentially irrelevant questions (e.g., about adherence in reference to an alert when they are actually adherent). This mirrors results from Roane et al. (2014) illustrating challenges of relying on prescription claims and diagnostic billing data for medication-related problem identification. ${ }^{30}$ In addition, CDS might not optimally emphasize referrals to community and/or other self-management resources. Often, participants did not view referral to resources as part of MTM. This result is consistent with CMS's previous discovery that fewer than a quarter of Part D plan sponsors provide any type of referral to resources, $9 \%$ provide general education newsletters, and only $5 \%$ provide educational materials after CMRs. ${ }^{11}$

Second, CMS could work with the Office of the National Coordinator for Health Information Technology and other participants to enact policies ensuring access by pharmacists to timely and accurate patient information. We found that decision making was influenced by the availability and accuracy of patient information in clinical information systems. Pharmacists desired information such as patient laboratory values, but despite evidence highlighting the importance of information sharing, information was commonly unavailable. ${ }^{31,32}$ Indeed, several health professional organizations, including the American Pharmacists Association, the American Medical Association, and the American Nurses Association, support health information exchange and interoperability among health care providers. ${ }^{33-35}$ However, these professional positions are not thoroughly supported by regulatory policies with regard to pharmacy practice. For example, pharmacists are ineligible for CMS's Electronic Health Record (EHR) Incentive Program and thus might be dissuaded from investing in EHR technology ${ }^{36,37}$ The recently launched Part D Enhanced MTM model will likely provide further insights, as participating plans might elect to request Medicare Parts A and B claims for beneficiaries to inform MTM delivery and will be using systematized nomenclature of medicine-clinical term codes to document MTM encounters. ${ }^{38}$

Third, CMS is advised to consider revisiting the required MTM standardized format for medication action plans and personal medication lists following CMRs. Participants at 3 of the 4 Later Maturity Level practices reported dissatisfaction with CMS's standardized format requirements, describing them as cumbersome and overwhelming for patients. ${ }^{39}$ These findings contrast with a survey by Cooke et al. (2015) of Part D beneficiaries who received MTM in that they reported few suggestions to improve CMS's standardized format. ${ }^{40}$ Additional research may be warranted.

Fourth, the allowance of more frequent CMRs by Medicare Part D MTM plans could be considered. CMS currently requires Part D plans to provide only 1 CMR annually. ${ }^{7}$ Part D was the only MTM payer for community-based Early Maturity Level practices, whereas Later Maturity Level communitybased practices had multiple payers, which ultimately enabled Later Maturity Level practices to provide more frequent followup. This also contrasts with the findings from Cooke et al., in that most patients surveyed perceived that more than $1 \mathrm{CMR}$ per year was unnecessary. ${ }^{40}$ However, the ability of Medicare beneficiaries to accurately self-assess their need for MTM and more frequent touchpoints is not well defined. Future research is warranted to ascertain optimal CMR frequency for different subgroups of patients. The findings of the CMS Enhanced MTM program, which permits flexibility in service provision, may assist with future decision making on this issue. ${ }^{38}$ 
Fifth, pharmacy associations and colleges of pharmacy should continue to support and provide education and training for support staff roles in MTM. In 2017, 87.3\% and 68.2\% of Part D MTM programs reported using pharmacy interns and pharmacy technicians, respectively, and $82 \%$ reported having pharmacy interns provide CMRs under pharmacist supervision. ${ }^{11}$ Given support staff's prevalent use and roles at Later Maturity Level practices, further development of training/ credentialing programs for support staff could be explored. For example, training in the use of scripted language to engage patients in MTM demonstrated improved patient acceptance. ${ }^{41}$ Also, Vande Griend et al. (2017) found that students increased the numbers of CMRs completed, and Freml et al. (2004) found students made more recommendations than pharmacists during "brown bag" reviews. ${ }^{42,43}$ However it's unknown how student involvement affects MTM service quality. Given the emphasis we observed novice users (students/interns) place on decision support, this warrants further research.

Finally, new MTM performance metrics could be considered to emphasize service quality rather than completion, as paralleled by other emerging value-based versus volume-based systems. ${ }^{44}$ This could result in an enhanced focus on patient self-management and referrals to community resources.

\section{Limitations}

This study has some limitations to consider. ACIC scores were intended to identify areas for further probing during subsequent interviews/observations; however, this wasn't always feasible because some participants ( $n=7$, including 1 pharmacist whose data were lost and not included in the analysis) deferred ACIC completion or returned the assessment at varying points during investigators' visits. Also, only pharmacist-provided MTM practices were included in this study. While all Medicare Part D MTM programs use pharmacists, some sponsors use nurses and physicians, and it is unknown whether findings are transferable to non-pharmacist delivery. ${ }^{11}$

Findings could have been influenced by researchers' backgrounds because the coding team consisted of 3 residencytrained pharmacists experienced in MTM and a research nurse. Coders with different professional training might have different interpretations.

By design, qualitative studies typically involve fewer subjects than quantitative studies, and we were successful in recruiting a diverse and purposeful sample of practices and identifying clear overarching themes, suggesting theoretical saturation was achieved. ${ }^{26}$ However, it is unknown whether our findings are transferable to other pharmacist-provided MTM practices or whether including more practices would have revealed additional themes.

Finally, the CCM guided our inquiry; different themes might have been identified from application of an alternative conceptual framework.

\section{Conclusions}

MTM delivery for Medicare Part D beneficiaries varies substantially, particularly by the practice's level of maturity. These findings provide evidence for several policy changes that could be considered to optimize MTM delivery, encourage alignment with the CCM, and promote practice maturation.

\section{Authors}

MARGIE E. SNYDER, PharmD, MPH, FCCP; HEATHER A. JAYNES, RN, MSN; WENDY M. LANTAFF, PharmD, MS, BCACP; and KAREN SUCHANEK HUDMON, DrPH, MS, RPh, Purdue University College of Pharmacy, Indianapolis, Indiana. STEPHANIE A. GERNANT, PharmD, MS, Nova Southeastern University School of Pharmacy, Davie, Florida, and WILLIAM R. DOUCETTE, PhD, University of Iowa College of Pharmacy, Iowa City.

AUTHOR CORRESPONDENCE: Margie E. Snyder, PharmD, MPH, FCCP, Purdue University College of Pharmacy, Fifth Third Bank Bldg., 640 Eskenazi Ave., Indianapolis, IN 46202. Tel.: 317.880.5429;

E-mail: snyderme@purdue.edu.

\section{DISCLOSURES}

This research and a portion of Snyder's salary were supported by grant number K08HS022119 from the Agency for Healthcare Research and Quality. The content is solely the responsibility of the authors and does not necessarily represent the official views of the Agency for Healthcare Research and Quality. Snyder reports consulting fees from Westat for an evaluation of the CMS Enhanced MTM program. The other authors have nothing to disclose.

Portions of this research have been presented as abstracts at the following conferences: (a) 2017 Academy Health Annual Research Meeting; June 25-27, 2017; New Orleans, LA; (b) 2015 American Society of Health-System Pharmacists Clinical Midyear Meeting; December 4-8, 2015; New Orleans, LA; and (c) 2014 North American Primary Care Research Group (NAPCRG) Annual Meeting; November 21-25, 2014; New York, NY.

\section{ACKNOWLEDGMENTS}

The authors acknowledge the other members of Dr. Snyder's K08 mentoring panel: Drs. Brad Doebbeling, Mick Murray, and Susan Perkins. The authors also acknowledge Michaela Fuesting and Lauren McCauley for assistance in preparing the manuscript.

\section{REFERENCES}

1. Lau DT, Stubbings J. Medicare Part D research and policy highlights, 2012: impact and insights. Clin Ther. 2012;34(4):904-14.

2. Centers for Medicare \& Medicaid Services. Medicare program; Medicare prescription drug benefit, final rule. Fed Regist. 2005;70:4193-585.

3. Agency for Healthcare Research and Quality. Effective health care program medication therapy management interventions in outpatient settings executive summary. 2014. Available at: https://effectivehealthcare.ahrq.gov/ sites/default/files/related_files/medication-therapy-management_executive. pdf. Accessed July 11, 2018.

4. Viswanathan M, Lahwati LC, Golin CE, et al. Medication therapy management interventions in outpatient settings: a systematic review and metaanalysis. JAMA Intern Med. 2015;175(1):76-87.

5. Bluml BM. Definition of medication therapy management: development of professionwide consensus. J Am Pharm Assoc. 2005;45(5):566-72. 
6. American Pharmacists Association, National Association of Chain Drug Stores Foundation. Medication therapy management in pharmacy practice: core elements of an MTM service model (version 2.0). J Am Pharm Assoc. 2008;48(3):341-53

7. Centers for Medicare \& Medicaid Services. Correction-CY 2017 medication therapy management program guidance and submission instructions. 2017. Available at: https://www.cms.gov/Medicare/ Prescription-Drug-Coverage/PrescriptionDrugCovContra/Downloads/ Memo-Contract-Year-2017-Medication-Therapy-Management-MTM-ProgramSubmission-v-040816.pdf. Accessed July 11, 2018.

8. Fox D, Ried LD, Klein GE, Myers W, Foli K. A medication therapy management program's impact on low-density lipoprotein cholesterol goal attainment in Medicare Part D patients with diabetes. J Am Pharm Assoc. 2009;49(2):192-99

9. Moczygemba LR, Barner JC, Lawson KA, et al. Impact of telephone medication therapy management on medication and health-related problems, medication adherence, and Medicare Part D drug costs: a 6-month follow up. Am J Geriatr Pharmacother. 2011;9(5):328-38.

10. Welch EK, Delate T, Chester EA, Stubbings T. Assessment of the impact of medication therapy management delivered to home-based Medicare beneficiaries. Ann Pharmacother. 2009;43(4):603-10.

11. Centers for Medicare \& Medicaid Services. 2017 Medicare Part D medication therapy management (MTM) programs. Available at: https://www.cms.gov/Medicare/Prescription-Drug-Coverage/ PrescriptionDrugCovContra/Downloads/CY2017-MTM-Fact-Sheet.pdf. Accessed July 11, 2018.

12. Centers for Medicare \& Medicaid Services. 2016 Medicare Part D medication therapy management (MTM) programs. Available at: https://www.cms.gov/Medicare/Prescription-Drug-Coverage/ PrescriptionDrugCovContra/Downloads/CY2016-MTM-Fact-Sheet.pdf. Accessed July 11, 2018.

13. Improving Chronic Illness Care. The chronic care model. Available at: http://www.improvingchroniccare.org/index.php?p=The_Chronic_Care_ Model\&s=2. Accessed July 11, 2018.

14. Wagner EH. Chronic disease management: what will it take to improve care for chronic illness? Eff Clin Pract. 1998;1(1):2-4

15. Ogallo W, Kanter AS. Using natural language processing and network analysis to develop a conceptual framework for medication therapy management research. AMIA Annu Symp Proc. 2016:984-93.

16. Ulin PR, Robinson ET, Tolley EE. Qualitative Methods in Public Health: A Field Guide for Applied Research. San Francisco, CA: Jossey-Bass; 2005. 17. Chang AC, Lincoln J, Lantaff WM, et al. Characterization of actions taken during the delivery of medication therapy management: a time-andmotion approach. J Am Pharm Assoc. 2018;58(1):61-66.e7.

18. Purdue University College of Pharmacy. Medication Safety Research Network of Indiana (Rx-SafeNet). Available at: http://www.pharmacy.purdue.edu/rx-safenet. Accessed July 11, 2018

19. Minnesota Pharmacy Practice-Based Research Network. Welcome to the Minnesota Pharmacy Practice-Based Research Network. Available at: http:// www.mpha.org/associations/9746/files/PBRN/index.html. Accessed July 11, 2018.

20. Improving Chronic Illness Care. Assessment of Chronic Illness Care: Version 3.5. Available at: http://www.improvingchroniccare.org/downloads/ acic_v3.5a.doc. Accessed July 11, 2018.

21. Bonomi AE, Wagner EH, Glasgow RE, VonKorff M. Assessment of Chronic Illness Care (ACIC): a practical tool to measure quality improvement. Health Serv Res. 2002;37(3):791-820.

22. Saleem JJ, Russ AL, Justice CF, et al. Exploring the persistence of paper with the electronic health record. Int J Med Informatics. 2009;79(9):618-28. 23. Beyer H, Holzblatt K. Contextual design. Interactions. 1999;6(1):32-42. 24. Irwin JY, Torres-Urquidy MH, Schleyer T, Monaco V. A preliminary model of work during initial examination and treatment planning approaches. Br Dental J. 2009;206:El.

25. Saleem JJ, Patterson ES, Militello LM, et al. Using human factors methods to design a new interface for an electronic medical record. AMIA Annu Symp Proc. 2007;640-44.

26. Bradley EH, Curry LA, Devers KJ. Qualitative data analysis for health services research: developing taxonomy, themes, and theory. Health Serv Res. 2007;42(4):1758-72.

27. McHugh ML. Interrater reliability: the kappa statistic. Biochem Medica. 2012;22(3):276-82.
28. Creswell JW, Plano Clark VL. Designing and Conducting Mixed Methods Research. Thousand Oaks, CA: Sage; 2007.

29. Paulk MC, Curtis B, Chrissis MB, Weber CV. Capability Maturity Model for Software, Version 1.1. Technical Report: CMU/SEI-93-TR-024. February 1993. Available at: https://resources.sei.cmu.edu/asset_files/ TechnicalReport/1993_005_001_16211.pdf. Accessed July 11, 2018. 30. Roane TE, Patel V, Hardin H, Knoblich M. Discrepancies identified with the use of prescription claims and diagnostic billing data following a comprehensive medication review. J Manag Care Pharm. 2014;20:165-73. Available at: https://www.jmcp.org/doi/10.18553/jmcp.2014.20.2.165. 31. Gernant SA, Zillich AJ, Snyder ME. Access to medical records impact on community pharmacist delivered medication therapy management: a pilot from the Medication Safety Research Network of Indiana (Rx-SafeNet). J Pharm Pract. January 1, 2017 [Epub ahead of print]. Available at: http:// journals.sagepub.com/doi/abs/10.1177/0897190017735422?url_ver=Z39.882003\&rfr_id=ori\%3Arid\%3Acrossref.org\&rfr_dat=cr_pub\%3Dpubmed\&. Accessed July 11, 2018

32. Arya V, Pinto S, Singer S. Understanding awareness of pharmacistled medication therapy management among primary care physicians in New York City, part II: findings and implications. J Med Pract Manage. 2013;29(3):187-94.

33. American Pharmacists Association. Policy manual: interoperability of communications among health care providers to improve quality of patient care. 2015. Available at: https://www.pharmacist.com/policy-manual?is_sso_ called=1. Accessed July 11, 2018.

34. American Medical Association. Physician-focused alternative payment models: reducing barriers H-385.908. 2017. Available at: https://policysearch. ama-assn.org/policyfinder/detail/health\%20information\%20exchange?uri= \%2FAMADoc\%2FHOD.xml-H-385.908.xml. Accessed July 11, 2018. 35. American Nurses Association. Standardization and interoperability of health information technology: supporting nursing and the national quality strategy for better patient outcomes. June 11, 2014. Available at: https:// www.nursingworld.org/practice-policy/nursing-excellence/official-positionstatements/id/standardization-and-interoperability-of-health-informationtechnology/. Accessed August 7, 2018.

36. Centers for Medicare \& Medicaid Services. An introduction to the Medicare EHR incentive program for eligible professionals. Available at: https://www.cms.gov/Regulations-and-Guidance/Legislation/EHRIncentive Programs/downloads/beginners_guide.pdf. Accessed July 11, 2018. 37. Centers for Medicare \& Medicaid Services. Promoting interoperability (PI). Available at: https://www.cms.gov/Regulations-and-Guidance/ Legislation/EHRIncentivePrograms/index.html. Accessed July 11, 2018. 38. Centers for Medicare \& Medicaid Services. Part D Enhanced Medication Therapy Management Model. Available at: https://innovation.cms.gov/initiatives/enhancedmtm/. Accessed July 11, 2018.

39. Centers for Medicare \& Medicaid Services. MTM program standardized format revisions. August 2017. Available at: https://www.cms.gov/ Medicare/Prescription-Drug-Coverage/PrescriptionDrugCovContra/ Downloads/MTM-Program-Standardized-Format-Revisions-v082917.zip. Accessed July 11, 2018.

40. Cooke C, Kaiser M, Natarajan N, Brandt N. Medicare beneficiary satisfaction with comprehensive medication review and the standardized format. J Manag Care Spec Pharm. 2015;21(10-a):S79-S80 [abstract U29]. Available at: https://www.jmcp.org/doi/pdf/10.18553/jmcp.2015.21.10.S1.

41. Miguel A, Hall A, Liu W, et al. Improving comprehensive medication review acceptance by using a standardized recruitment script: a randomized control trial. J Manag Care Spec Pharm. 2017;23(1):13-21. Available at: https:// www.jmcp.org/doi/10.18553/jmcp.2017.23.1.13

42. Vande Griend JP, Rodgers M, Nuffer W. Effect of an advanced pharmacy practice experience on medication therapy management services in a centralized retail pharmacy program. J Manag Care Spec Pharm. 2017;23(5):561-65. Available at: https://www.jmcp.org/doi/10.18553/jmcp.2017.23.5.561. 43. Freml JM, Farris KB, Fang G, Currie J. Iowa priority's brown bag review medication reviews: a comparison of pharmacy students and pharmacists. Am J Pharm Ed. 2004;68(2):Article 50.

44. Centers for Medicare \& Medicaid Services. What are the value-based programs? 2018. Available at: https://www.cms.gov/Medicare/QualityInitiatives-Patient-Assessment-Instruments/Value-Based-Programs/ValueBased-Programs.html. Accessed July 11, 2018. 